\title{
Article \\ An Assessment of Spatio-Temporal Characteristics of Lightning Occurrence with Elevation, a Case of Uganda
}

\author{
Peter Wasswa ${ }^{1,2, *}$, Geoffrey Sabiiti ${ }^{2,3}$, Harriette Okal1, 5 , Paul Kato ${ }^{4}$, Joyce Lunyolo ${ }^{2}$ and Harriet Namulindwa ${ }^{6}$ \\ 1 Institute for Water Research, Rhodes University, Grahamstown-South Africa \\ 2 Department of Geography, Geo-informatics and Climatic Sciences, Makerere \\ University, Uganda \\ 3 IGAD Climate Prediction and Applications Centre \\ 4 Department of Economics and Statistics, Kyambogo University, Uganda \\ 5 University of Embu, Kenya \\ 6 Uganda National Meteorological Authority \\ * Correspondence: waswapeter4@gmail.com
}

\begin{abstract}
:
Lightning has received a lot of attention in scientific literature during the recent decade, not only because it is an impressive atmospheric phenomenon but also its associations with severe storms that cause unprecedented damages to agriculture, electric power networks, property and life. This study assessed the spatio-temporal characteristics of lightning occurrence with elevation in Uganda using lightning flash and elevation datasets for a period of fifteen years (1998-2013). Datasets used in this study included daily lightning flashes as captured by Lightning Imaging Sensor (LIS) aboard on Tropical Rainfall Measurement Mission (TRMM) satellite and elevation data in form of Digital Elevation Model (DEM) obtained from the Shuttle Radar Topography Mission (SRTM). Spatio-temporal results indicated that $\sim 80 \%$ of areas with an elevation that ranges from 800-1200 m above mean sea level (masl) in Uganda had severe lightning occurrences and $\sim 20 \%$ of areas with an elevation greater than $1200 \mathrm{~m}$ (masl) had severe lightning occurrences. The country received an enhanced number of lighting events with the highest number in 1999. Subsequently, a reduced trend was observed from 2002 to 2007 followed by an increment in the number of lightning events in (2010, 2011, 2012 and 2013). The intensity of the events decreased gradually though two peaks were observed, (1998-2001) and (2010-2013). Furthermore, results indicate escalations in the frequency and duration of lightning events from 60 times in 1998 to approximately 200 times in 2013 and from 1000 microseconds in 1998 to more than 2000 microseconds in 2013. Generally, the country experienced an enhanced increase in lighting occurrences over the study period which therefore calls for urgent actions to combat the root cause and also provide effective measures to reduce the impacts of lightning strikes.
\end{abstract}

Keywords: Spatio-temporal; Lightning; Elevation; Uganda 


\section{Introduction}

One of the most spectacular meteorological phenomena and the most devastating weather event that affects people directly or indirectly worldwide is lightning [1]. There are roughly 2000 thunderstorms in progress around the world at any given time, producing about 30 to 100 cloud-to-ground flashes each second or about five million flashes a day [2]. It has been observed that lightning is a hazardous and potentially destructive weather event that is among the causes of weather-related damages and economic losses over the world [3].

Lightning is a massive electrostatic discharge caused by the circulation of warm moisture-filled air through an unbalanced electric field in the atmosphere, accompanied by loud sounds of thunder [4]. There are two types of lightning produced by thunderstorms; cloud-to-ground (flashes of lightning between a thunderstorm and the earth) and intra-cloud (flashes of lightning within a thunderstorm), with cloud-to-ground accounting for $25 \%$ of lightning occurrence globally and it affects man.

Lightning injuries are the most frequent injuries by natural phenomenon and often results in high mortality rates, ranging from $20 \%$ to $30 \%$ globally [5]. The effects of lightning range from minor to life-threatening. The immediate manifestations in survivors of lightning include changed consciousness, disorientation, impaired vision, ruptured eardrums, hearing loss, seizures (electrical activity in the brain), paralysis, burns on the skin, and internal burns to organs, tissues and finally cardiac arrest [5].

Lightning-related human injuries have become a grave problem in many parts of Africa for the past decade [6, 7]. Among lightning affected countries in Africa, Uganda has recorded surprising worst cases of lightning in world history in the last decade where lightning incidents, including the death of 18 school children and their teacher in 2011 [8]. Based on the recent lightning strike incident assessment report carried out in Uganda, the frequency and intensity of lightning accidents have markedly been increasing in the past few years [8].

The causes of these escalating observed lightning problems are not yet much known, however, studies like $[9,10$, and 11] have linked lightning occurrences to certain surface properties which include elevation, terrain slope and vegetation. These studies discovered that lightning strikes showed a positive relationship with elevations above $800 \mathrm{~m}$ and that no relationship was found in the areas of low-lying topography. However, despite the increasing lightning fatalities in Uganda, studies concerning lightning frequency and intensity with elevation are still scanty.

This study, as a result, is based on two specific objectives; (i) to assess the spatiotemporal relationship of lightning occurrence and elevation in Uganda and (ii) to determine the characteristics associated with lightning occurrence in Uganda. There has been an increased outcry of lightning strikes in Uganda and yet the main root cause has been a nightmare to trace. Therefore in this study, to overcome this national challenge, lightning occurrences within Uganda will be examined and more emphasis will be put on its frequency, duration and relationship with elevation.

\section{Materials and Methods}

Uganda (Fig1) is positioned between longitudes 29० $34^{\prime}$ and $35^{\circ} 29^{\prime}$ East, and latitudes $4^{\circ} 12^{\prime}$ North and 1'29' South, with an elevation of 1000 to $1300 \mathrm{~m}$ (masl). The Western part of the country is also separated by the Western Rift Valley running from North to South with an elevation of 600-900 m (masl). In the South-Eastern corner of the country, exists Africa's largest lake, Lake Victoria. Other significant water bodies include Lake Albert, Lake Edward and Lake George in the west and Lake Kyoga in the center. The country experiences an equatorial climate (over the Lake Victoria Basin), continental (Northern Uganda), semi-arid (Northeastern Uganda), and montane climate over mountainous and 
highland areas [12] with annual rainfall totals varying from 500-2800 $\mathrm{mm}$ and the mean annual surface temperatures around $21^{\circ} \mathrm{C}$.

To assess spatio-temporal characteristics of lightning occurrence with elevation in Uganda, datasets for daily lightning flashes as captured by Lightning Imaging Sensor (LIS) was obtained from on aboard Tropical Rainfall Measurement Mission (TRMM) satellite (available from http://thunder.nsstc.nasa.gov) and elevation data in form of Digital Elevation Model (DEM) obtained from the Shuttle Radar Topography Mission (SRTM) (available from https://www2.jpl.nasa.gov/srtm/). The LIS datasets used in this study have a record from 1998 to 2013 with a temporal and spatial resolution of $2.5^{\circ} \times 2.5^{\circ}$ grid with 24 hours mean annual cycle resolution. The dataset was incorporated into the ArcGIS10.2.2 platform to allow for the exploration of relationships of lightning strikes with surface characteristics-elevation.

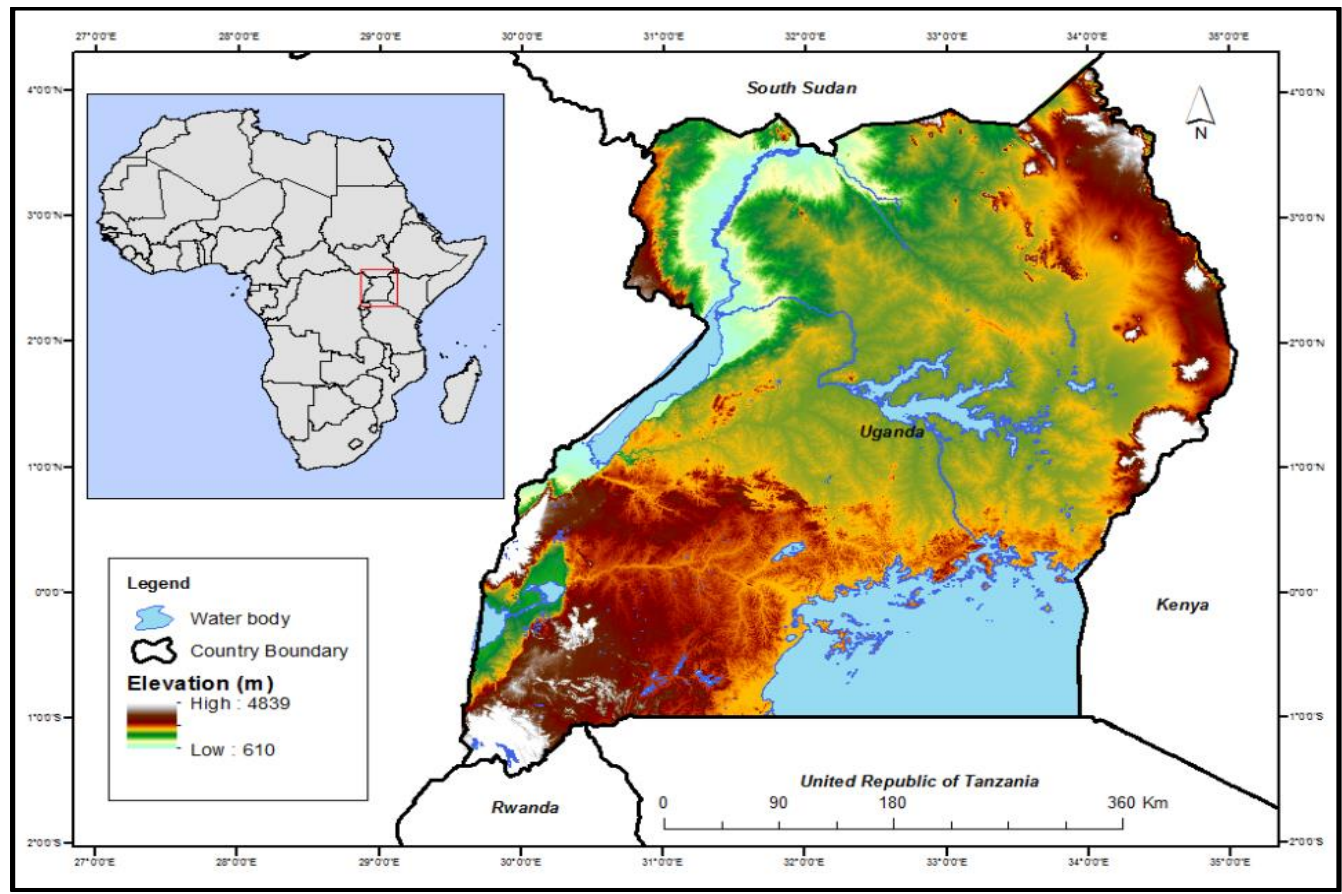

Fig 1. Map of Uganda showing the distribution of water bodies and elevation

To assess the spatio-temporal characteristics of lightning occurrence in Uganda, spatial maps of lightning occurrences were drawn and interpolated using Inverse Distance Weighting (IDW), a GIS analysis technique for the period of 15 years from 1998 to 2013. To establish the relationship between lighting occurrences and elevation, DEM dataset was converted into contours with a space interval of $200 \mathrm{~m}$ using the Contour Tool in ArcMap and were superimposed on the interpolated lightning occurrence maps of Uganda. The lightning intensities were analysed using the Wavelet Transform (WT), which is a relatively novel, very precise for signal, and time series processing [13] method. This was executed in MATLAB while lighting frequencies and events durations were plotted in R software (version 4.2.1).

\section{Results}

\subsection{Spatio-temporal relationship of lighting occurrence with elevation in Uganda}

The reason for the assessment of a possible relationship between lightning activity and elevation is the recognized role of orographic lifting to enhance convection and consequently leading to lightning. Spatio-temporal results (Fig 2) indicates that for the whole study period, Uganda had severe lightning occurrences $\sim 80 \%$ in areas with an elevation that ranges from $800-1200 \mathrm{~m}$ and $\sim 20 \%$ in areas with an elevation greater than 
$1200 \mathrm{~m}$ (masl). This behavior could be due to the convective activities that develop within organized low-pressure systems that are accompanied by frontal activities in areas whose elevations are (800-1200) $\mathrm{m}$ and these are areas with tremendous water bodies like L.Victoria, L. Kyoga, L. Albert, L. George, L. Edward and the great River Nile Waters, thus making the orographic forcing trivial. These results are in agreement with [14] whose study revealed that the steep topographic gradient rather than altitude is responsible for producing deep convection. Additionally, enhancement of convection within frontal thunderstorms is not related with the high elevation itself as enhancement of precipitation [10]. It is observed that the country received tremendous lightning activities in 1998, 1999, 2001, 2004, 2007, 2008, 2009, 2010, 2011 and 2012.

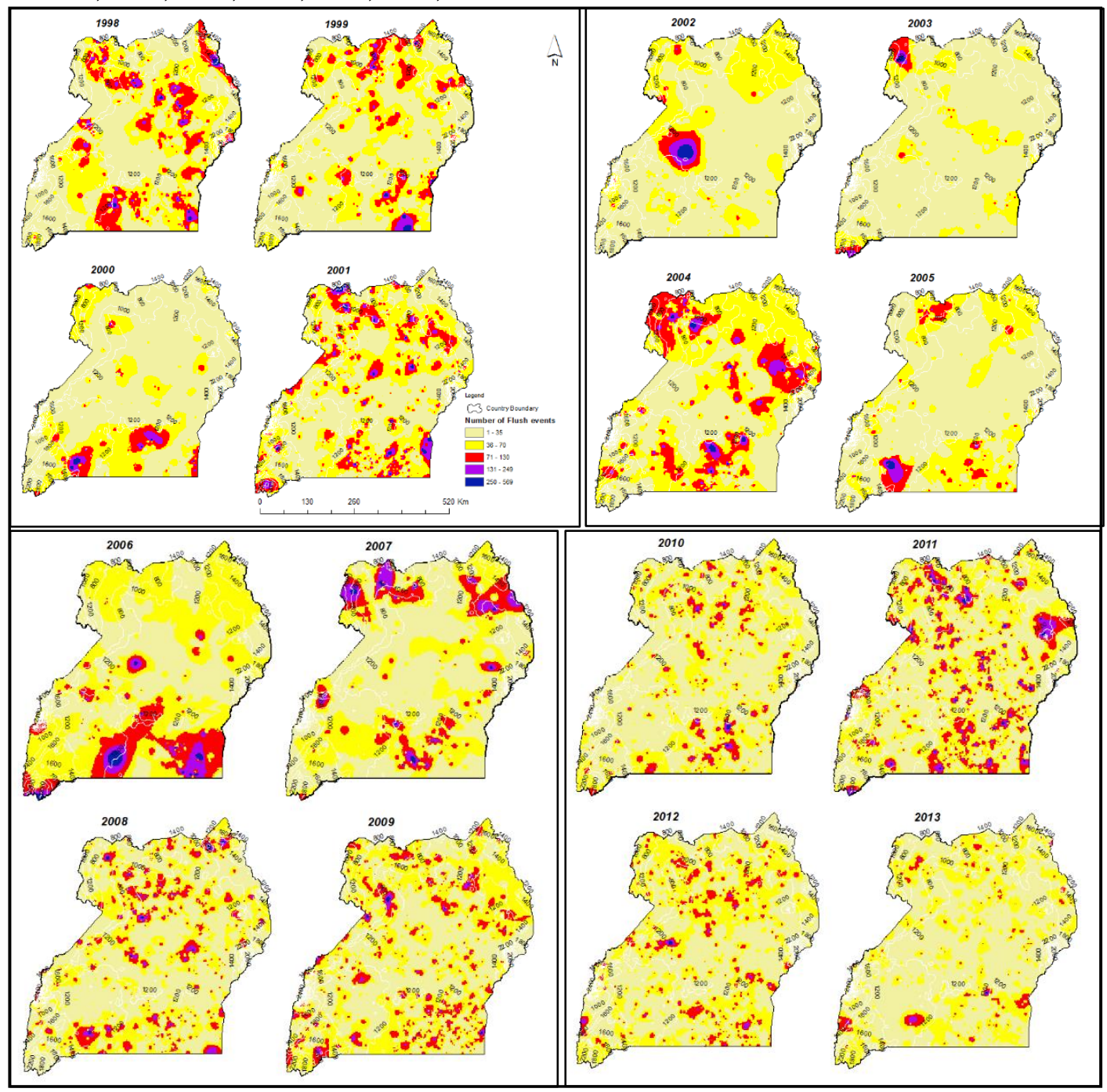

Fig 2. Spatio-temporal lightning occurrences over Uganda

\subsection{Characteristics associated with lightning occurrences in Uganda}

To determine the characteristics associated with lightning occurrences in Uganda, data were analysed on basis of the total lighting events, lightning intensity, frequency and duration taken by lighting events when they strike. Results from (Fig 3) indicate that the country received an enhanced number of lightning events during the early years of the study (1998-1999) with 1999 (46) obtaining the highest number of lightning events. Then, thereafter, a reduced trend was observed from 2002 to 2007. An increment in the number of lightning events was observed during the last years (2010, 2011, 2012 and 2013) of the study period. This trend is in agreement with [8], whose findings indicated increasing surprising worst cases of lightning strikes in Uganda. 


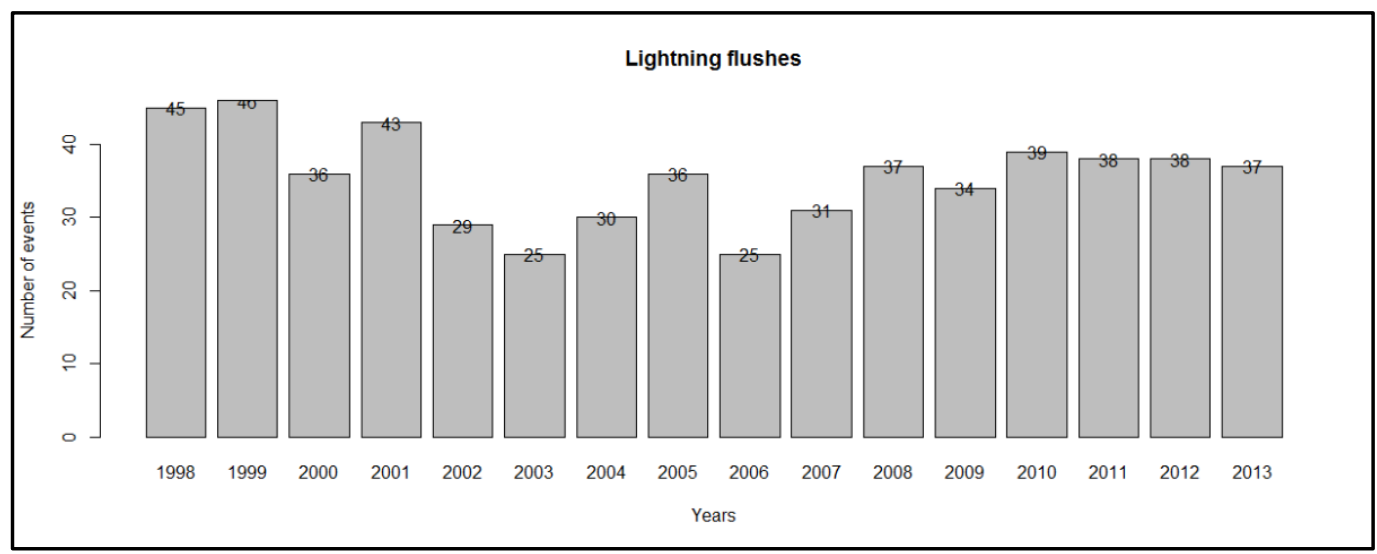

Fig 3. Number of lightning events

The continuous Morlet wavelet analysis was applied to the multiple timescale analysis of average lightning flashes over Uganda (Fig 4). The mother wavelet was chosen because it provides a good balance between time and frequency resolutions and identifies quasi-periodic fluctuations in a variety of geophysical time series. Results from (Fig 4 a) indicated three cycles of lightning intensity with 1998 to 2001 (increased intensity), 20022007 (decreased intensity) and 2008-2013 (increased intensity). Within the 95\% confidence level, the wavelet power spectrum shown in (Fig 4 b) reveals more concentration between 1-2 year band cycles as the dominant period of variability which confirms that these times had strong annual lightning intensity signals. Also in the Cone of Influence (COI), (Fig 4 b) reveals the presence of a 1-year cycle as the dominant period of lightning intensity variability persisting approximately from 1998 to 2001 and a 2-year oscillatory cycle from 2003 to 2013.

On the global wavelet power spectrum, the annual lightning intensities of the time series were confirmed by the integration of power over time (Fig $4 \mathrm{c}$ ). Results revealed only one significant peak above the $95 \%$ confidence level for the global wavelet spectrum, assuming that $\alpha=0.439$ (red noise area) represented by the dashed lines. Results from (Fig $4 \mathrm{~d}$ ) show an average overall scale of 2 years, and give a measure of the average year versus time. This plot, therefore, showed a slightly decreasing trend of annual lightning intensity variance over Uganda from 1998 to 2013.

Over the period of study, the frequency of lightning events has been increasing from 60 times in 1998 to approximately 200 times of lighting events in 2013 (Fig 5). It should be noted that over the study period, there has been a significant increase in the durations taken by a lightning event when it strikes. Results from (Fig 6) shows that lighting durations have been increasing from 1000 microseconds in 1998 to more than 2000 microseconds in 2013. 


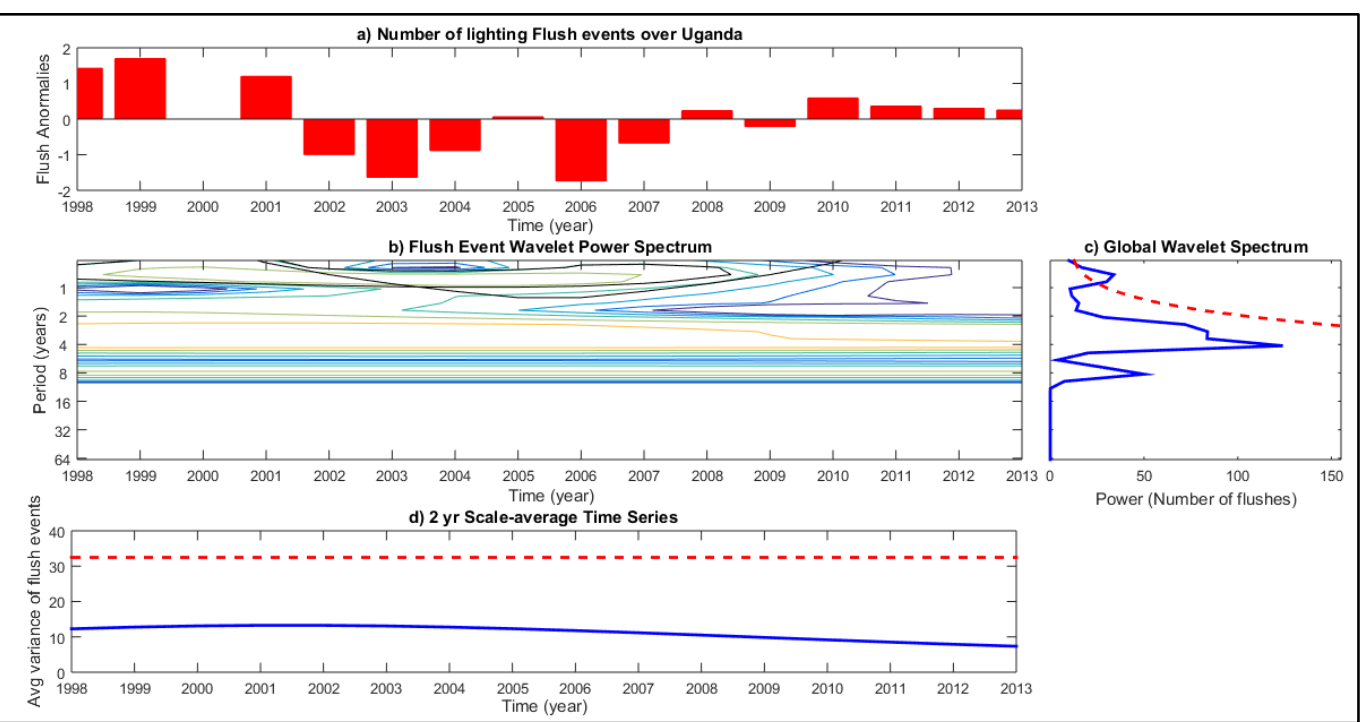

Fig 4. (a) Yearly lightning intensities over Uganda. (b) The wavelet power spectrum for lightning intensities. (c) The global wavelet spectrum (no. of events). The dashed line is the $5 \%$ significance level for the global wavelet spectrum, and (d) Scale-average wavelet power over the 2-year band. The dashed line is $95 \%$ confidence.

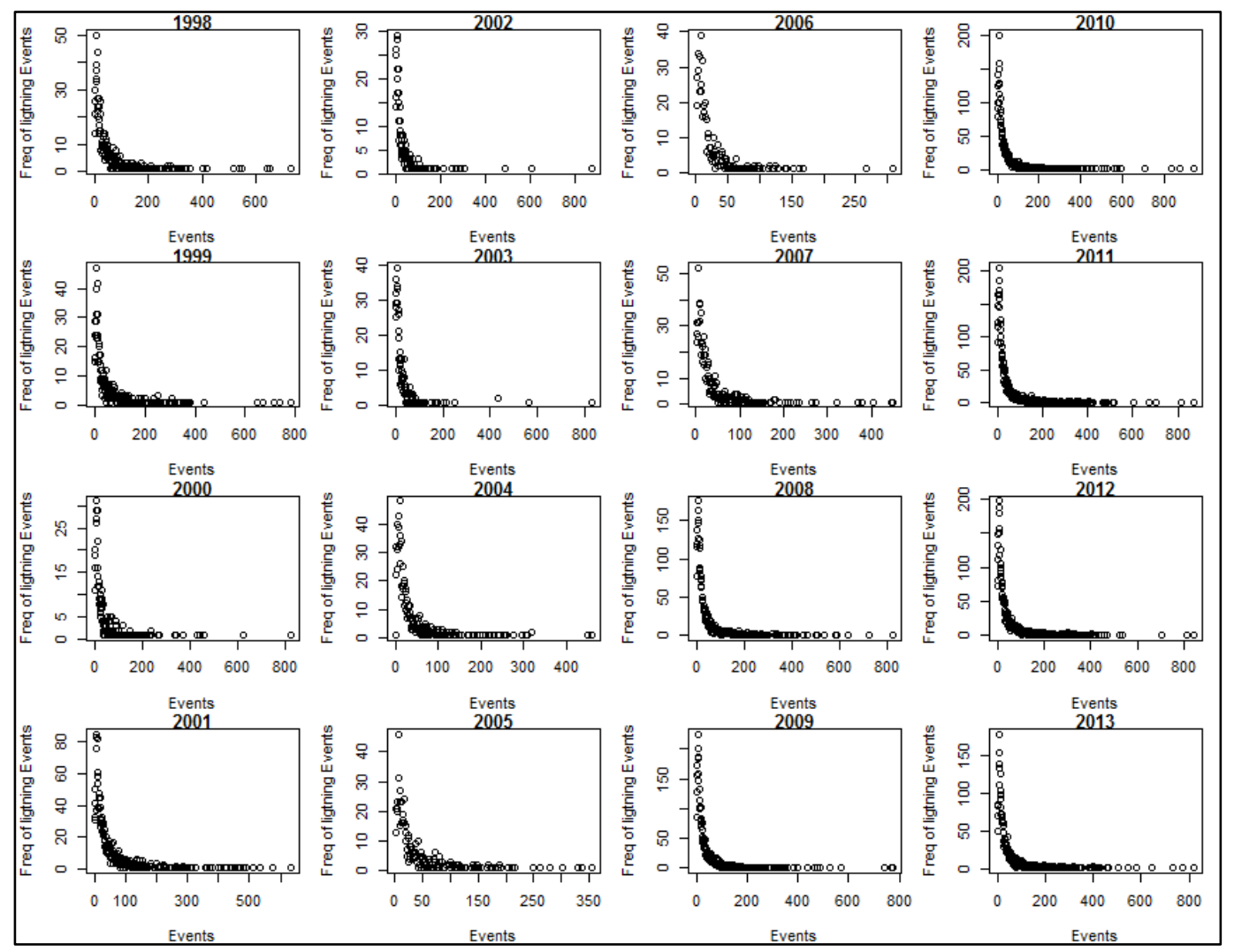

Fig 5. Frequency of lighting events over Uganda 


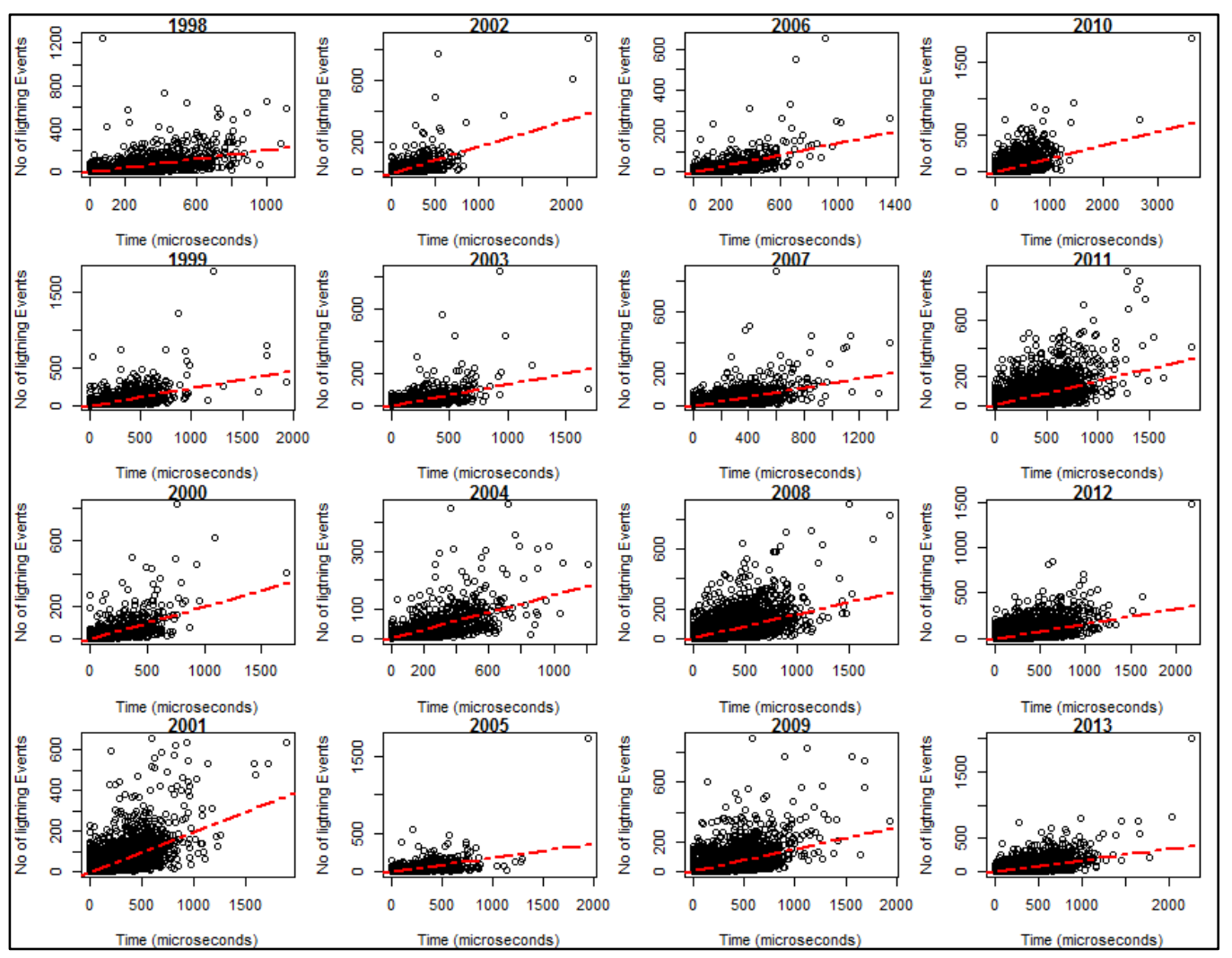

Fig 6. Duration of lighting events over Uganda

\section{Discussion}

This study has revealed outcomes in assessing the spatio-temporal characteristics of lightning occurrence with elevation in Uganda. Spatio-temporal results indicated that for the whole study period, Uganda had severe lightning occurrences $~ 80 \%$ in areas with an elevation that ranges from $800-1200 \mathrm{~m}$ and $\sim 20 \%$ in areas with an elevation greater than $1200 \mathrm{~m}$. The severe lightning occurrence was found in areas with an elevation that ranges from 800 to $1200 \mathrm{~m}$ (masl) and these are areas with tremendous water bodies like L.Victoria, L. Kyoga, L. Albert, L. George, L. Edward and the great River Nile Waters, which experience enhanced convective activities as stated by [14]. The country received an enhanced number of lighting events with the highest number in 1999 (46). Then, a reduced trend was observed from 2002 to 2007 followed by an increment in the number of lightning events in (2010, 2011, 2012 and 2013). This trend is in agreement with [8], whose findings indicated increasing surprising worst cases of lightning strikes in Uganda. The intensity of lightning events decreased gradually over the study period although two peaks (1998-2001) and (2010-2013) were observed. Furthermore, results indicate increases in the frequency and duration of lightning events from 60 times in 1998 to approximately 200 times of lighting events in 2013 and from 1000 microseconds in 1998 to more than 2000 microseconds in 2013. These results are alarming and have put Uganda on the hotspot list of lightning prone countries in the world according to $[7,8]$. It should be noted that these results are in agreement with $[6,8]$ whose studies found a remarkable increase in the frequency and intensity of lightning accidents in the past few years in Uganda. 


\section{Conclusion}

This study acts as a foundation for the current and future lighting occurrence characteristics research throughout Uganda given the fact that there has been an increase in lightning fatalities in Uganda but studies concerning the lightning frequency and intensity with elevation are scanty. Results indicate increasing severity, frequency and duration of lightning strikes in areas within the lake basins having elevations that range (800-1200) $\mathrm{m}$ (masl). Therefore, this study recommends that further studies in relation to spatiotemporal characteristics of lightning events with convective activities associated within the lake basins should be done as this prove to have a strong linkage with high lightning strikes. In addition, the government and local authorities should provide lightning arrestors to the people who live in the lake basins of Uganda to reduce the dangers that come from lightning strikes.

Author Contributions: Conceptualization, PW, HN and PK. Methodology, PW, KP, JL and HN. Software, PW and HO. Formal analysis, PW, HO and PK. Investigation, PW, HN and PK. Data curation, PW. Writing-original draft preparation, PW, PK, JL and HN. Writing - review and editing, HO and GS. Visualization, PW, GS, HO and PK.

All authors have read and agreed to the published version of the manuscript.

Funding: This research received no external funding.

Data Availability Statement: The data used to support the findings of this study are readily available from the corresponding author upon request.

Acknowledgements: We would like to thank Tropical Rainfall Measurement Mission (TRMM) and NASA team for producing and making datasets used in this study available and Institute for Water Research, Rhodes University-Grahamstown-South Africa for giving us a platform to write this manuscript.

Conflicts of Interest: The authors declare no conflict of interest.

\section{References}

1. Alex, N., Nalwanga, F., Mugume, I., Ogwang, B. A., \& Wasswa, P. (2021). A community perspective of flood occurrence and weather forecasting over Kampala City. African Journal of Environmental Science and Technology, 15(5), 188-201.

2. Evert, R., \& Schulze, G. (2005, July). Impact of a new lightning detection and location system in South Africa. In 2005 IEEE Power Engineering Society Inaugural Conference and Exposition in Africa (pp. 356-363). IEEE.

3. Curran, E. B., Holle, R. L., \& López, R. E. (2000). Lightning casualties and damages in the United States from 1959 to 1994. Journal of Climate, 13(19), 3448-3464.

4. Prakash, C., \& Tayal, I. (2013). Different presentations of victims of lightning during thunderstorm. Journal of Indian Academy of Forensic Medicine, 35(3), 203-205.

5. Aslan, S., Yilmaz, S., \& Karcioglu, O. (2004). Lightning: an unusual cause of cerebellar infarction. Emergency medicine journal, 21(6), 750-751.

6. Wasswa, P., Tanner, J., Sabiiti, G., Ojara, M., Okal, H., Kato, P., \& Namulindwa, H. (2021). An Investigation on Spatiotemporal Variability of Drought Events under Different Climate Change Scenarios, Case Study: Rakai District.

7. Borgerhoff Mulder, M., Msalu, L., Caro, T., \& Salerno, J. (2012). Remarkable rates of lightning strike mortality in Malawi. PLoS One, 7(1), e29281.

8. Mary, A. K., Gomes, A., Gomes, C., \& Ahmad, W. F. W. (2014, October). Lightning hazard mitigation in Uganda. In 2014 International Conference on Lightning Protection (ICLP) (pp. 1770-1779). IEEE. 
9. Oulkar, S., Siingh, D., Saha, U., \& Kamra, A. K. (2019). Distribution of lightning in relation to topography and vegetation cover over the dry and moist regions in the Himalayas. Journal of Earth System Science, 128(7), 1-17.

10. Kotroni, V., \& Lagouvardos, K. (2008). Lightning occurrence in relation with elevation, terrain slope, and vegetation cover in the Mediterranean. Journal of Geophysical Research: Atmospheres, 113(D21).

11. Kilinc, M., \& Beringer, J. (2007). The spatial and temporal distribution of lightning strikes and their relationship with vegetation type, elevation, and fire scars in the Northern Territory. Journal of climate, 20(7), 1161-1173.

12. BakamaNume, B. B. (Ed.). (2010). A contemporary geography of Uganda. African Books Collective.

13. Torrence, C., \& Compo, G. P. (1998). A practical guide to wavelet analysis. Bulletin of the American Meteorological society, 79(1), 61-78.

14. Choudhury, B. A., Goswami, B. N., Zahan, Y., \& Rajesh, P. V. (2021). Seasonality in power law scaling of convective and stratiform rainfall with lightning intensity over Indian Monsoon regions. Atmospheric Research, $248,105265$. 